HOW VICTIMS CONCEPTUALIZE THEIR EXPERIENCES OF HATE CRIME

\title{
How Victims Conceptualize Their Experiences of Hate Crime
}

\author{
Mika Andersson, Caroline Mellgren, and Anna-Karin Ivert \\ Department of Criminology, Malmö University
}

\begin{abstract}
Author's note
The present article is part of the doctoral dissertation of Mika Andersson "Hate crime: Consequences and Interpretations", published in June 2018. As is customary in Sweden, the dissertation was publicly defended by the author, opponent was professor Barbara Perry at University of Ontario Institute of Technology. The dissertation and the defense were consecutively approved by a reviewing committee consisting of docent Anita Heber at Stockholm University, professor Berit Wigerfelt at Malmö University, and doctor David Wästerfors at Lund University.
\end{abstract}

\begin{abstract}
The aim of the study is to provide the victims' perspective to the contemporary conceptualization of hate crime. Much attention has been given to the interpretational frameworks of offenders, and although victims' definitions of hate crime are sometimes mentioned in passing in interview studies, this has never been a primary subject of study.

The present study applies phenomenological analysis to 28 semi-structured interviews with victims of hate crime. The results show that the participants primarily apply meaning to their experiences in social groups and use previous experiences to guide their interpretations. While the conceptualization of victims largely concurs with theory presented by the research community and special interest organizations, they diverge from how hate crime is contextualized in hate crime legislation.
\end{abstract}

Keywords: hate crime, victimization, victim perspective, phenomenology 


\section{HOW VICTIMS CONCEPTUALIZE THEIR EXPERIENCES OF HATE CRIME}

\section{Introduction}

The authors of the present study explore how victims define and create meaning from their experiences of hate crime, which is an understudied aspect of the victim perspective. A growing body of research details the physical, psychological, and social harm inflicted on individuals and groups targeted by those who commit hate crime (McDewitt, Balboni, Garcia \& Gu, 2001; Iganski \& Lagou, 2015; Pezzelia \& Fetzer, 2017); however, harm is only one limited aspect of the victim experience. Focusing solely on harm may lead to unintended problems, as critics argue that it assigns a passive role onto victims which can result in negative objectification (Lindegren, 2004). Moreover, it remains unknown whether the labels and interpretational frameworks used by victims of hate crime are congruent with the labels used by civil rights organizations, the justice system, and the scientific community.

In this study, hate crime is defined as threats, harassment, physical and/or sexual violence motivated by prejudice of the victims' race, origin, culture, religion, sexual orientation, gender identity or expression, and/or disability. The study is based on interviews conducted as part of the Experiences and Exposure to Hate Crime (EEHC) study - a mixed-method study regarding hate crime victimization of Swedish university students.

\section{Conceptualizing Hate Crime}

\section{Theoretical Development}

The examination of hate crime as a scientific concept and field of study was initiated by legal scholars examining issues of procedural justice and culpability. Lawrence (1994) identified two distinct conceptualizations of hate crime in a legal context: 1) the discriminatory selection model, and 2) the racist animus model. In the first model, hate crime is defined as incidents in which the offender selects the victim due to their perceived group belonging. This definition does not place demands on a bias of negative sentiment toward the group belonging of the victim. The second model refers only to incidents evidently motivated by negative bias toward the group belonging of the victim. Lawrence (1994) is in favor of the second model, arguing that it accurately captures the unique and specific core of hate crime as a phenomenon and offers higher levels of procedural justice.

During the second half of the 1990s, hate crime increasingly became a topic of interest for social scientists (for example, Jeaness \& Grattet, 2001, and Boeckmann \& Turpin-Petrosino, 2002). Perry's (2001) definition of hate crime from the early 2000s has remained the leading definition for researchers within the field of hate crime studies. She concurs with Lawrence (1994) in conceptualizing hate crime as structural but clearly sets herself apart in approaching hate crime from a sociological rather than legal perspective. She defines hate crime on a high level of abstraction aiming to capture its inner properties and mechanisms and argues that hate crime is the result of two processes (Perry, 2001): 1) Othering and 2) Doing Difference. Othering refers to a collective practice that involves the social construction of normative ideals. The normative ideal in turn needs and invokes its binary opposite, the Other. The Other is perceived as abnormal and is subjected to social stigmas. The process of Doing Difference 


\section{HOW VICTIMS CONCEPTUALIZE THEIR EXPERIENCES OF HATE CRIME}

can be understood as an enactment of these social identities, carried out with the purpose to uphold and maintain social hierarchies. To summarize, Perry holds that "Hate crime, then, involves acts of violence and intimidation, usually directed towards already stigmatized and marginalized groups. As such, it is a mechanism of power and oppression, intended to reaffirm the precarious hierarchies that characterize a given social order" (Perry, 2001:10).

More recently, Chakraborti and Garland (2012) represent a new theoretical wave criticizing previous conceptualizations of hate crime. Rather than approaching hate crime as a consequence of established institutions, they argue that hate crime can be circumstantial, with its primary causes in temporal and spatial factors in which victims are selected due to their perceived vulnerability rather than group belonging (Chakraborti \& Garland, 2012). This perspective responds to research showing that many hate crime offenders appear to have a low-bias commitment, and therefore, a low level of racism, homophobia, et cetera (ibid.). However, Arendt (1973) argues that individuals who perform acts of prejudice in a manner of perceived neutrality are likely to have a high level of prejudice rather than a low level. Consequently, the phenomenon that Chakraborti and Garland (2012) interpret as an indicator of low levels of prejudice may indicate that the prejudice has reached a state or normalization. Nevertheless, Chakraborti and Garland (2012) have contributed greatly to the critical debate concerning the eligible motives in legal frameworks by arguing that they fail to protect the most vulnerable groups, for example the homeless (Wacholz, 2005; Al-Hakim, 2014), alternative subcultures (Garland \& Hodkinson 2015), and sex workers (Campbell, 2014). Furthermore, Chakraborti and Garland (2012) have lifted the necessity to study hate crime victimization as an intersectional phenomenon, where socially constructed group belongings, health, and lifestyle patterns interact.

\section{The Victim Perspective}

Much attention has been given to the interpretational frameworks of offenders, as seen in Lawrence (1994) on culpability, Perry (2001) on the process of doing difference, and Chakraborti and Garland (2012) in their discussion of the perceived vulnerability of victims. In cases where the experiences of victims are presented, the role of the interpreter of the event is rarely in question. Instead, the psychological, social, and physiological consequences of hate crime are lifted (see Lawrence, 1994; Perry, 2001; Chakraborti \& Garland, 2012).

It is only in the theory development concerned with answering the question of why hate crime victims report more extensive psychological damage compared to non-bias victims (see for example McDewitt, et al., 2001; Iganski \& Lagou, 2015; Pezzelia \& Fetzer, 2017) that a first step is taken to approach the internal world of victims. It is believed that victims of hate crime are more affected because these incidents target the self of the victim. Although victims' definitions of hate crime are sometimes mentioned in passing in interview studies on the consequences of hate crime, it has not been the primary subject of study. Such studies indicate that victims perceive hate crime as motivated by a bias towards an aspect of their identity shared by a larger collective (see for example Iganski, 2001; Willis, 2008; Williams \& Tregidga, 2013). However, it remains unexamined if bias-motivated attacks directed at a collective identity is also perceived as attacks on the victim's self. 


\section{HOW VICTIMS CONCEPTUALIZE THEIR EXPERIENCES OF HATE CRIME}

Special interest organizations are often assigned the role of victim representatives in Swedish domestic politics (see for example SOU, 2000:88). However, the narratives of special interest organizations tend to mirror the offender perspective. The latter is observable in reports from organizations working for sexual minorities (RFSL, 2017), cultural minorities such as the Roma minority (Ds. 2014:8), and racial minorities such as the African-Swedish minority (Mångkulturellt centrum, 2014). Like Perry (2001), these organizations explain hate crime on a high level of abstraction and place its causes in systematic and structural oppression (Mångkulturellt centrum, 2014, Ds. 2014:8, RFSL, 2017).

Several factors contribute to the disinclination to take the perspective of victims into consideration when conceptualizing and defining hate crime.

From a legal position, it is likely connected to the principle of culpability which is centered on the intent of the offender. Further, the Swedish justice system in general has been criticized for forcing victims into a passive bystander role to their own conflict (Lindegren, 2004). The victim is instructed to retell the event as detailed as possible, and in part, to offer information about any eventual damage they may have suffered (Lindegren, 2004; Karmen, 2010). However, it rests with the court to interpret and assign meaning to the testimony of the victim, and the court holds the mandate to sanction the offender insofar that certain criteria are met (ibid.). In summary, the victim is largely treated as an object rather than subject (Lindegren, 2004).

The researchers' focus on hate crime offenders is likely connected to scientific notions of causality. Given that the offenders are taken to represent the catalysts, they are essential in any etiology of hate crime. Further, from a crime prevention perspective, it is crucial to understand the driving forces of offenders and causal circumstances of these events.

The tendency to refrain from presenting victims as subjects may be due to the cultural conflict between narratives of victim blaming and victim defending. Victim blaming narratives generally present victims of crimes as subjects that provoke the offender to such a degree that they are in part or in whole to blame for the incident in question (Karmen, 2010). In contrast, victim defending narratives generally present victims as objects who have no responsibility for the incident (ibid.). A stable narrative in which the victim is not blamed, yet at the same time remains a subject, appears to be largely absent in Nordic culture (Christie, 1986). In a narrative climate governed by these victim archetypes, it becomes rhetorically counterproductive for organizations to assign victims the role of subject, as it is associated with guilt.

The focus on victim harm within the justice system among researchers, interest groups, and policy debate is also likely the result of genuine concern; therefore, an adequate problem description is needed in the development of victim support. However, there is also a need to extend the scope of study to the definitions and meaning making of victims, as it is of utmost importance that legal actors and support services have knowledge about the labels and interpretational frameworks of victims in situations of police reporting and treatment. Further, it is important to assign victims the role of subjects and interpreters and not reduce them to mere objects, as this role inhibits recovery (Herman, 2015; Chahal, 2017). 


\section{HOW VICTIMS CONCEPTUALIZE THEIR EXPERIENCES OF HATE CRIME}

\section{The Present Study}

\section{Aim}

The aim of the study is to provide a victim perspective to the contemporary conceptualization of hate crime. Firstly, we do not know if victims concur with the narratives lifted by special interest organizations and governmental parties whereby hate crime is conceptualized as part of structural oppression. Secondly, we do not know if the legal conceptualization regarding acts and protected group categories correspond to victims' experiences and definitions (see for example Mason-Bish, 2014, on the problem of intersectionality) nor do we know if victims label their experiences as hate crime or use other interpretational frameworks. Lastly, we do not know if victims of hate crime perceive the incidents as targets on their selves, as proposed by Iganski (2001).

\section{Method}

Participants in the interview study were recruited as part of a larger study called Experiences and Exposure to Hate Crime (EEHC). The overall purpose of EEHC was to map experiences of hate crime among the students at Malmö University, a university located in a medium-sized city in the south of Sweden. In the EEHC questionnaire, hate crime is defined as experiences of verbal or written threats, harassment or bullying, being followed or chased, minor assault (being hit with an opened hand, having one's hair pulled, or similar), assault and aggravated assault (being hit with a closed fist, kicked, or attacked with a weapon or other object), sexual molestation (being subjected to unwanted sexual acts such as touching, kissing, grabbing, or fondling), rape, robbery, and burglary perceived by the victim to be motivated by prejudice directed towards their religion, disability, origin/background, sexual orientation, sex, and/or gender.

A survey was distributed during fall semester, 2013, to a total of 4649 students, in which 2853 participated. On the last page of the questionnaire, information was given about an upcoming interview study held during the spring semester of 2014 and students could leave contact information if they wanted to participate. 52 hate crime victims left contact information, of which 28 participated in an interview. The most common reason for not participating was that the person no longer lived in Malmö, often because they were abroad on student exchange programs for their thesis. The durations of the interviews ranged from 35 to 120 minutes, with the majority being around 60 minutes. The present study is based upon these interviews. For an extended description of the method of the EEHC, see Andersson (2018).

The sample method comes with epistemological implications that must be acknowledged. The age of the participants spanned from 19 to 36, with few over 26. Only two participants were part of a family with children of their own. Therefore, the results are more representative of a young victim group with a student lifestyle.

Student samples are often more representative of individuals from a middle and upper-class background. However, Malmö University has a comparatively high proportion of students from a non-academic background - a pattern also mirrored by the participants in the interview study. Furthermore, self-selected student samples are likely to exclude those with ongoing and 


\section{HOW VICTIMS CONCEPTUALIZE THEIR EXPERIENCES OF HATE CRIME}

deep traumatization. However, it needs to be noted that some of the participants were survivors of deep and long-lasting trauma due to previous experiences of hate crime, usually during young adolescence.

The authors of the present study hold that the interviews should be regarded as co-created narratives formed by the interaction between the researcher who conducted the interviews and the participants. The interviewing researcher was white, 27 years-old at the time of the interviews and transgender, but primarily interpreted as a woman. The interviewing researcher's style of clothing during the interviews was feminine, and they was of average weight, had short hair, glasses, a septum/nose piercing, and visible tattoos when wearing short-sleeved clothing.

To the experience of the interviewer, men and women talked openly about gender roles and the social expectations they are subjected to based on their gender identity and expression. Most of the female participants assumed the interviewer has had experiences of cat-calling and similar forms of sexual harassment as well as experiences of intimate relationships with men who ascribe themselves a conservative gender role. Non-white participants were usually more reserved in comparison to white participants at the beginning of the interview. The interviewing researchers needed to confirm that they had a theoretical understanding of what it means to be a person of color living in a society in which whiteness is the norm. These participants further opened up when the interviewer did not question, reject, or deny their experiences of racism, and became comfortable when they followed up by asking questions that affirmed these experiences. That the interviewing researcher had knowledge of political events and the media debate concerning issues related to LGBT and racial minority rights appeared to further improve the trust and comfort level of these participants in the interview situation. Most interviews took place at Malmö University, but two of the participants preferred to be interviewed at home. The participants were able to choose whether they wanted to be recorded or not, to which all approved. The interviews were transcribed prior to analysis. The driving motivation to partake in the interview study was to contribute in helping other victims.

Most participants had experiences of repeat victimization, and 18 had experienced hate crime with intersecting motives. Fifteen had been victimized due to their national, ethnic or cultural origin, eight had been victimized due to their sexual orientation, twenty due to their sex or gender, five due to their religion and/or cultural background, and three due to their disability. All of the participants had experiences of harassment, bullying, and/or threats, twelve had experiences of sexual abuse, and had experiences of physical violence. Four of the interviews were conducted in English, and the rest were in Swedish. Quotations from the Swedish interviews have been translated by the authors. The researchers have chosen to exclude descriptions of incidents or details that would impinge upon the participants' right to remain anonymous.

\section{Analysis}

The present study applies phenomenological analysis as presented by Husserl in Ideas I-III (2012, originally published 1931), the Crises of European Sciences and Transcendental 


\section{HOW VICTIMS CONCEPTUALIZE THEIR EXPERIENCES OF HATE CRIME}

Phenomenology (1970, originally published 1936) and is further guided by Bjurwill (1995). The analytical focus on the essence of experiences provided by phenomenology offers a strategy for assessing how victims of hate crime create meaning from their experiences and how the phenomena of hate crime appears to them. The analytical method presented by Husserl is one focused on the nodal connections between the following aspects of a certain phenomenon: experience, ideation, generalization, nuancing and constitution. The process of analysis is non-linear and the core of the phenomenon is gradually unfolded in several waves.

The analysis of experience and ideation includes describing the phenomena and identifying its essence and particularities (Husserl, 1970, 2012; Bjurwill 1995). In the present study, this corresponds to the parts of the interviews in which the participants were asked how they defined the term 'hate crime' and describe their experiences of such events. Generalization refers to a process of further identifying the boundaries and singularities of the phenomena by relating and contrasting it to other concepts (ibid.). The data used to analyze this aspect in the present study is primarily based on the answers given by participants when asked to describe what they perceived as the difference between a crime with and without a hate crime motive. Participants also came to reason around the difference between hate crime, discrimination, and various forms of legal expressions of prejudice. These narratives were also assessed when analyzing generalization. Nuancing refers to viewing or looking upon the phenomena from different perspectives in order to gain a fuller picture of it (ibid.). This process is conducted by the researcher rather than the participants and consists of comparing the stories of the participants. While experience, ideation and generalization are conducted to get closer to the phenomena, nuancing allows the researcher to take a step back and view it from an external vantage point. Lastly, constitution is the analysis of how the phenomenon is created before us (ibid.). For Husserl, this last step is the closest we can ever come to understanding human nature and psychological disposition (Husserl, 1970, 2012). It is in this step that the researcher examines the process through which the phenomenon is perceived (ibid.), which can be described as the nodal center where experience, ideation, generalization and nuancing meet.

It is further expected that the phenomenon exists in a state of constant retention and protention. Present experiences are thereby given meaning and content in relation to previous experiences, retention, and an anticipated future, protention (Husserl, 1970, 2012).

Consequently, narratives in which previous experiences and future expectations are presented have been selected for analysis.

As previously stated, the present study departs from a given definition of hate crime and some phenomenologists might shun such an approach (for an example of conducting phenomenological research on hate crime, see Salter and McGuire, 2015) as Husserl proposes an inductive analysis untainted by pre-understanding. However, he also clearly states that a certain degree of pre-understanding is necessary for the possibility of intentionality and scientific exploration (Husserl, 1970, 2012).

\section{Results}

The results are presented in five parts: identities and their markers, making sense of prejudice, 


\section{HOW VICTIMS CONCEPTUALIZE THEIR EXPERIENCES OF HATE CRIME}

manifest expressions, story arcs, and constitution. How the participants form an understanding of their group belongings and the markers that signal belonging to the group in question are presented under the section, "Identities and Their Markers". Thereafter, the participants' understanding of the preconditions and motivation of their offenders are summarized in "Making Sense of Prejudice". The acts that the participants define as hate crime are summarized in "Manifest Expressions". How the participants come to create meaning from their experiences of hate crime is presented in "Story Arcs", and finally, the abstract process through which the phenomena are constituted for the participants is presented in the "Constitution" section. As this last part is an inductive analysis of the previous results rather a direct analysis on the data, it does not contain any quotations from the participants.

\section{Identities and Their Markers}

All participants conceptualized hate crime as involving acts of prejudice targeting one or several group identities of the victim. The participants placed emphasis on the group aspect of identity as the identity targeted in these incidents was perceived to be shared by a larger collective rather than comprised by a unique quality of the victim:

I believe that a hate crime is carried out because the offender does not respect the group that the victim belongs to. Eh, by group I mean, like, sex, gender, sexuality, skin color, race, class, age. [...] But, yeah, the crime is committed because that person is the way they are.

But that's it, isn't it? That it is directed toward, like, a person or group because of who they are. So, it's not a coincidence. I mean, they're women, or LGBT, or part of a political or religious minority.

The categories of group identities that the participants listed as examples varied greatly. Most included ethnicity, nationality, race, gender, and sexual orientation, and a few included political opinions and age. These group identities became visible to offenders through the presence of certain markers. Markers expressing sexual orientation were perceived to consist of certain aesthetic expressions in clothes and hairstyles, body language, and showing affection to a same-sex partner. Markers perceived to be connected to religion consist of displaying certain religious symbols such as hijab, cross, or Kippah. The color of one's skin, eyes, and hair, along with accents and clothes of non-western fashion were perceived as markers of race. Similarly, gender was perceived as connected to bodily form and body language. A participant who was assaulted due to her race and religion expressed herself in the following way:

I believe that if I am victimized, then others who look the same [as me] will also be subjected to the same thing, I think. Because if they look like me, have the same clothes, and like, look the same, as immigrant as me, and have the veil like me, then they get the same thing, probably, if they are unlucky.

The excerpt also serves as an illustration of the logical consequence of the notion that hate crime targets an identity shared by a larger collective, namely, that the offender may also target others who share the same identity marker. This aspect is generally referred to as 


\section{HOW VICTIMS CONCEPTUALIZE THEIR EXPERIENCES OF HATE CRIME}

interchangeability by researchers and has been lifted by hate crime victims in several studies (Noelle, 2002; Iganski, 2001; Perry, 2015).

Most participants described how various markers come together to shape how they are perceived by others. The following comment made by a Muslim woman when describing the visibility of her faith in connection to her gender and nationality while in public spaces in Sweden:

I think we give it different names and put it in different categories, but usually it's very connected. Usually, people can't tell that he's Muslim [referring to her husband who is white], but for me, one can automatically tell. [...] They place me in this big category of Somali people. When I didn't have a headscarf on, it was different - 'Okay, she looks like these Somali people, but then she doesn't wear a headscarf, so she's civilized.'

The intersection of religion and nationality or skin color was mentioned by the five participants who had experienced anti-religious hate crime. Further, women often described how racist incidents would also be gendered, and sexual minority women and men alike described homophobic incidents as connected to gender expression. For example, two women of color described how they would be sexually and racially harassed more often if they wore clothes associated with their cultural background. Similarly, a white woman described how she would be harassed by neighbors because she was perceived as a "white whore". For sexual minority participants, the connection to gender had more to do with transgressing expectations based on conservative gender roles, for example, by displaying feminine body language while at the same time having a body culturally coded as male.

Some participants had identity markers that they described as occasionally visible. These participants describe how they can choose to show their group identity to others and use this knowledge to avoid victimization when spending time in environments that are perceived as unsafe or hostile. Participants who had a foreign or minority background but passed as white described how talking without and accent and avoiding being dressed in ways associated with their cultural background, while LGBT participants placed a focus on body language and dressing in neutral colors.

\section{Making Sense of Prejudice}

The participants were uniform in their opinion that hate crime is distinguished from other crimes by the presence of prejudice. Prejudice was referred to as negative sentiments targeting certain identity markers, such as body language or skin color. The prejudice was either held to be a key motivator for the offender when initiating the crime and/or a tool for victim selection:

I think a regular crime can be directed at anyone, while a hate crime makes a difference between people and people - that one views some as better or worse than others - and that it is used as an excuse to commit crimes against some but not others. 


\section{HOW VICTIMS CONCEPTUALIZE THEIR EXPERIENCES OF HATE CRIME}

Some participants described how the cultural meaning connected to identity markers changes over time. LGBT participants described an increased openness, while Muslim participants experienced a growth in hostility. This increase in insecurity among Muslim populations post 9/11 in a western context has been observed in previous research (for an overview, see Iganski \& Levin, 2015).

Participants primarily traced the origin of hate crime and prejudice to social structures. These structures were perceived to consist of hierarchical systems with a norm at the top. Participants referred to the norm in different ways: as a position of power, as an ideal, as a standard for social institutions and social relationships, and/or as a position that grants social privilege. The following quotation is an excerpt in which the participant talks about the risk of being subjected to hate crime victimization. He describes how he was targeted because he, in his own words, has a flamboyant body language that transgressed traditional gender expectations. The interviewing researcher followed up by asking if he believed that the risk of being subjected to hate crime was equal for everyone, to which he responded,

No, I have difficulties [imagining that] - to be [...] an invisible group and be subjected to a hate crime [...] if you blend in well and don't get grouped, then no one will feel any hatred towards you either.

The excerpt above also illustrates how the norm was occasionally perceived as a neutral "nongroup".

Though the participants acknowledged that the risk of being subjected to hate crime varies greatly between different groups, most held that majority and minority populations alike should be protected by hate crime legislation. Some explained that power structures are variable, although protection should apply to everyone regardless of their position in a present hierarchy; others argued that it would be principally wrong to differentiate between groups. Those who argued in favor for protection of minority populations only did so by referring to structural circumstances. For example, one participant said that it is a different thing for a lesbian to be targeted due to her sexual orientation than it is for a heterosexual because lesbians also experience structural inequality and disadvantage due their orientation.

The norm in a social hierarchy was often perceived as connected to the sizes of different groups in which those numerically larger have a higher status. However, participants did acknowledge that social hierarchies may not necessarily be tied to a population size. One participant, who initially described hate crime as involving incidents targeting minority groups only, mentioned sexual minorities, people of color, and women as examples of victim groups. When asked to develop how she came to include women as a minority, she responded with the following:

Um, well, I mean, like, in power relations and all that, you always find that gender comes into play. I mean, like, the set-out norm is [...] that when you're a woman, you're deemed as inferior $[. .$.$] because power relations dictate that.$

The path through which participants arrived at the conclusion that prejudice is located on a structural level varied. For most, it was an insight reached gradually along with repeat 


\section{HOW VICTIMS CONCEPTUALIZE THEIR EXPERIENCES OF HATE CRIME}

experiences of hate crime, hate incidents, micro-aggressions, and discrimination.

Accumulated over time, these experiences lead the participants to conclude that they live in a society in which a large part of the population and sometimes also societal institutions devalue them based on their group identity markers. Others describe encountering theories of social hierarchies through social networks or education. In a reflexive way, most came to understand their experiences as structural due to both lived experiences and theory.

That hate crime is structural in origin also led to the conclusion that it is but one expression of a greater whole. The following quotation is from a participant who describes the difference between how she used to perceive and react to hate crime as a teenager and as an adult:

Perhaps you see more of a structure in it. Before, you just got irritated, and now you get sort of furious. [...] Yeah, you see a power structure express itself in many different ways that you might not have thought about before when you were younger.

Fewer participants reflected on prejudice on an individual level. Those who did reasoned that socialization into certain values and beliefs produce a fear of individuals who are believed to be essentially different from oneself:

I believe that hate crime builds upon incomprehension - that you can't feel any belonging to a person because of how they look or behave or where they come from. That they have an incompatibility, and regard themselves as incompatible, with the person and are almost afraid of the person and have to diverge this threat.

This prejudice is also depicted as containing elements of dehumanization. The following excerpt is an illustrative example of being reduced to the representation of a negative stereotype based on one single identity marker or a combination of identity markers, which was an experience shared by all the participants:

It was so evidently directed towards my skin color somehow. It was as if I did not exist as a human being or perhaps wasn't even human $[\ldots]$ it was very dehumanizing.

The prejudice expressed in hate crime thus reduces the victim to a negative stereotype, void of any other social content. This aspect of prejudice denies the participants agency and possibility to represent themselves by attaching their own content to their markers and to decide what markers are socially relevant in any given situation.

\section{The Manifest Expressions of Hate Crime}

The following sections contain a summary of the acts that the participants described as hate crime. Most participants used the Swedish label, 'kränkning', when asked what kind of acts hate crime consists of. This label has no direct translation into English but can be explained as a violation carried out in a derogatory way. This is the same label used in Swedish legal frameworks, but the participants often expressed uncertainty about the threshold at which an act can be said to turn into a hate crime. One participant who had experienced repeat verbal 


\section{HOW VICTIMS CONCEPTUALIZE THEIR EXPERIENCES OF HATE CRIME}

slurs, threats, and derogatory comments from strangers for as long as she could remember expressed herself the following way when asked if she categorized these incidents as hate crime:

No, I don't know. I think, um, that hate crime is something more physical? It is just that, that feeling, you know. But then, no, it does not have to be, because when I think more about it, it can also be like online hate and those kinds of things.

The first impulse of the participant was to exclude verbal violence from the label of hate crime, only to question the same impulse when given the opportunity to dwell on it for a brief moment. In general, the participants felt confident in identifying acts as prejudiced but not in identifying their legal status:

I have come to understand that there are several types of crimes. It does not have to be physical. It can also be verbal, [as in] threats and those kinds of things, and I guess that it is a gray zone on the internet also, like how you label a hate crime, but I guess it can be both verbal and physical [...] I don't know what is strictly legal and what is [the difference between] how you feel violated and how you label it legally. I don't know, really.

It is clear that the legal system in Sweden which distinguishes hate crime from other forms of prejudiced acts is counterintuitive for hate crime victims. The threshold for where legal forms of prejudice end and hate crime begins is difficult to identify. Instead, the participants experienced hate crime as a minor part of a greater hierarchical system. As such, they are but one expression of prejudice, and the master signifier at hand for victims was not the label 'hate crime' but rather the labels for various hierarchical systems, such as heterosexism, patriarchy, racism, and the like.

Prior experiences of acts that express the presence and maintenance of such a system is a major contributor to how the participants created meaning from the present events. These include micro-aggressions, othering, discrimination, and daily talk among people in their personal sphere that express prejudiced opinions. The excerpts below are from two participants who discuss the normalization of sexualized violence towards women; the first in relation to their own previous experience and the second participant in relation to conversations she has had with her friends:

Um, you're used to it somehow [...] I've been used to it since I was little. These gender roles are so strong that guys always shout things [out at] you and grab you. It's like you grow up inside it.

Particularly, female friends here in Malmö - almost everyone - they recognize [how] people start following you when you're going home from a pub.

Similarly, experience of hate crime influences how micro-aggressions and acts of discrimination are interpreted. For example, the participants perceived as female and who engaged in same-sex relationships described how their sexual orientation would often be interpreted by others to be a strategy for gaining sexual attention by males in the vicinity 
HOW VICTIMS CONCEPTUALIZE THEIR EXPERIENCES OF HATE CRIME

rather than acts performed for their own pleasure. Occasionally, these incidents would erupt into harassment, threats, and/or violence when the participants would declare that they were not sexually available to the man or the men who showed interest. In these incidents, the previous sexual objectification of what is interpreted to be staged lesbianism turned into disgust upon the realization of its authenticity. The presence of these experiences led the participants to attach a different kind of meaning to their more common experiences of sexual objectification; the male/males in their vicinity were not only reducing them into a stereotype but also held the potential threat of violence.

The characteristics of the incidents described as evident hate crime incidents varied depending on the kind or kinds of prejudice they were based on. Evidently, misogynistic hate crime was described as acts in which the offender attempts or succeeds to subject the victim to rape or sexual harassment by means of violence or threats of violence. The following quotation was from one of the women who had been raped:

I couldn't do much. Like I said, he was a guy, and they are usually much stronger, and he was fit too, so it was really hard. I mean, I tried to [get] away, turn away, but I couldn't. And then I tried to scream, but he covered my mouth.

Important to these cases is the absence of consent along with the presence of objectification and sadism. For example, in the case quoted above, the lack of consent was evident, as the participant tried to use physical strength to fight her offender off and scream for help. She also presented the offender as sadistic and compared him with a fictive character that is a sadistic rapist.

Acts of evidently racist hate crime was described as incidents whereby the victim was subjected to threats or violence while the offender used derogatory language about the origins of the victim or declaring that the victim is not welcome in Sweden due to their origins. For women of color, these evidently racist hate crimes also encompassed sexual harassment in public places, rape, and threats of sexual violence based on racial stereotypes. The following quotation is from when a participant spoke about being sexually harassed at pubs and clubs:

I think it's more because of my race and less because I'm a woman, but I mean, they both play a part, you know. But the fact that I'm black, because you don't see that coming, you don't see them doing that much to white ladies in the club.

Homosexual, bisexual, or transphobic hate crimes were perceived as threats, harassment, or violence whereby the victim is subjected to derogatory comments about their gender expression, their sexual orientation, or is referred to as mentally ill, sick, sinful, or perverse. Among participants who were interpreted as lesbian, evident incidents also included threats of sexual violence if they rejected the sexual advances of certain heterosexual men.

Lastly, incidents perceived as evidently anti-religious hate crime were encompassed by hate speech, threats, gestures, harassment, physical violence, and vandalism whereby anti-religious sentiments are expressed. For example, one participant described how a group of masked men did the Hitler salute outside of a restaurant owned by a Jewish family on the day of a Jewish feast. 


\section{HOW VICTIMS CONCEPTUALIZE THEIR EXPERIENCES OF HATE CRIME}

Some of the participants had experiences of what they had difficulties to classify. These ambivalent incidents were sometimes described as incidents whereby the offender appears to make a victim selection due to bias but does not express this in an explicit way. One participant, a woman of color, described how a stranger suddenly spat and shouted at her in an open street in the middle of the day. She explained that she interpreted the incident as racist because there were no other people of color around. It appeared to her to have been a selection made by the offender, but she could not be entirely certain.

This man - an old Swedish man - saw me, and then attacked. Nobody else was black or a foreigner - goodness, was he upset! Really, really upset. He started spitting on my side and shouting.

Other incidents that were perceived as ambivalent were ones that appeared to originate from personal conflict as well as prejudice. One participant described that he was physically abused by a group of men who used derogatory language about his origins. The participant remained uncertain as to whether the incident was "purely" a hate crime, given that he had a romantic relationship with the leading offender's ex-girlfriend at the time of the incident. He reasoned that he might not have been physically abused had it not been because of the relationship.

\section{Story Arcs}

How the participants created meaning from their experiences of hate crime was personally connected to the meaning making they had attached to previously lived experience, here referred to as story arcs. The process was also reciprocal, as the interpretation of previous experience could change in the light of new events. The process of applying meaning to events is sometimes conducted in solitude in the form of inner reflection and analysis. However, most story arcs develop in intimate social groups of family and/or friends as they share experiences with one another. The first of the excerpts below was made by a participant who reflected on the situation of talking with his family about racist incidents, and the second was made by a participant who reflected on talking with her friends about homophobic incidents:

I turn to my family [...] we talk very openly when it comes to these sorts of things.

I sat and thought about how it sometimes is, like, you know, 'This weird person said this to me when we passed,' and it can be, like, 'No, but they've said it to me as well. Don't care about it. It's just someone sitting there talking nonsense.' [It's] sort of communion through victimization.

The participants describe turning to individuals in their family and/or community of friends who they believe share their experiences. These were generally individuals who had the same identity markers and spent their time in a similar cultural context. The sharing of experiences and meaning making were related in a reflexive way, co-producing the interpretations held by the participants. The interpretations were thereby non-static in nature and developed over time. One example is from a participant who explained how her lived experience before moving to Sweden had not prepared her with an understanding of how afro-phobia expresses 


\section{HOW VICTIMS CONCEPTUALIZE THEIR EXPERIENCES OF HATE CRIME}

itself. She grew up in what she describes as a non-racist context in which interracial relationships and cross-cultural exchanges were common. She realized that she experienced racism in Sweden when one of her friends identified an incident as racist.

I started to connect events after a friend told me that one thing was very racist a thing someone did - I thought, 'Oh, if that was racist, I have experienced that.'

Another participant explained that her first experiences of racism were in school during her early teenage years. She was repeatedly physically abused by a group of teenagers who were active in the white power movement. She described how the teachers labeled these incidents as bullying rather than racially motivated hate crimes. She did not feel that the label of bullying addressed her experiences correctly but lacked the theoretical resources needed to identify them as racist.

The shared interpretational frameworks of events also reflect the place that the participants perceive themselves to hold within a social hierarchy. The notion of what place is held in a social hierarchy is further formed by narratives from outgroups. Occasionally, this results in a dual understanding of what it means to belong to a certain group, as those who have identity markers endowed with social stigma by outgroups must navigate contradicting narratives. One homosexual participant described how his family attached negative meaning making to his markers from a very young age:

She [mother] has often called me 'sissy' and 'faggot' and those kinds of things my mother - ever since I was young. So, I guess that it also meant that my brother took after it ever since we were kids and called me that too, and as a result, I $[\ldots]$ already from an early age understood that it is something negative - to be called that all the time.

It was not until late puberty when he became friends with a bisexual woman that he began to come across positive narratives and non-demeaning meaning making about homosexuality.

This notion of "my place in a social hierarchy" also generates expectations about the future. The participants' place in the social hierarchy was often understood from a combination of different perspectives, and occasionally these conflicted. The comment below was made by a participant with experiences of homophobic incidents. The excerpt is from a part of the interview where she discusses her expectations of being a teacher and the prospects of being openly homosexual in future workplaces. After reflecting on her own need for LGBT role models as a teenager, discussing the matter with friends, and reading a book about living a "double life", she reasoned that she could be open to her future colleagues but not to her pupils.

I do my internship at a school now [...] I told my supervisor and asked her what I should do if they ask. I am not in a relationship now, but if they ask and I am [in a relationship] later on. And then she said, 'I would recommend that you don't say anything and keep a low profile.' 
HOW VICTIMS CONCEPTUALIZE THEIR EXPERIENCES OF HATE CRIME

While recognizing that she would have appreciated having an openly gay teacher herself, she also realized that such openness may not be beneficial for her in her role as a teacher, as it would leave her vulnerable to harassment.

There was no consensus among the participants as to whether the incidents were perceived as connected to their personhood or not. Generally, participants who had a strong connection to the social community of the group associated with the identity marker defines the incidents are more personal, while individuals who had no or very little connection to the social community represented by their identity marker experienced their victimization as less personal. However, this is a crude simplification, as there appear to be many factors that influence the extent to which victimization was held to be personal.

Firstly, the accuracy of the offenders' classification was major contributor. Several participants describe being wrongly categorized as belonging to a certain group. These incidents were described as threatening and intimidating but not as connected to their personhood. Such incidents were instead described as testimonies of a bigoted society. A participant who received racist comments on notes left in her school locker said,

I thought, 'Don't I have the right to be in Sweden?' It did not matter that I did not have a foreign background because it is so extremely violating. My parents have always been anti-racist, so I knew. I thought it was so sad that this person believed that not everybody in Sweden has the right to be here.

Secondly, the way the offender behaves can contribute to whether the incident is perceived as personal or not. A transgender participant who had experiences of homophobic threats compared two events and described why they felt that one of these targeted them personally and not the other. In the first incident, the participant and their partner was verbally threatened by a woman while waiting at a bus stop. In the second incident, the participant and their friends were verbally threatened by a man when walking home after a club.

It was very personal, [the incident] with the mother. It was me and my partner, but it was me. She looked me straight in the eyes [demonstrates by staring intensely into my eyes]. The guy, on the other hand, he was drunk [and said], 'Fucking dykes!' [makes a sweeping gesture with her arm to illustrate his body language, but does not look into my eyes]. It was not against me in the same way.

Thirdly, the interchangeability was described by some participants as an aspect that made the incidents feel less personal, as anyone sharing the identity marker could be targeted. The following is a quotation from a participant who had been sexually harassed:

Because it was a stranger, and therefore it felt more like, anyone who was also a woman and walked there would have been subjected [to the same thing].

A final important aspect for the connection between victimization and personhood of was the navigation of contradicting narratives along with objectification. As stated earlier, the offender attacks a negative stereotype in hate crime incidents. The victim does indeed know that the negative stereotype exists but does not identify with it. Rather, the victim creates their own 


\section{HOW VICTIMS CONCEPTUALIZE THEIR EXPERIENCES OF HATE CRIME}

meaning and context around their marker which is positively loaded. Consequently, the target is not perceived as their self-identity, but the acts remain a violation of the self, as the victim is denied self-representation by being reduced to a negative stereotype.

\section{Constitution}

The abstract process through which the phenomena was constituted for the participants include common processes. The interpretation of a hate crime incident was initially guided by the content of the incident itself: the presence of violence or threats along with the use of derogatory language targeting an identity marker of the victim. This direct and symbolic content was thereafter related to previous experiences that resembled the incident in question. The resemblance was, in part, drawn from outer circumstances such as the time and place of the incident, the age of the offender, whether the offender was intoxicated or not, and the like. It was also drawn from emotional states: the victim recalls previous experiences when they felt the same kind of distress and/or pain. This is an instant process that aids the victim to assess the situation and take necessary actions to get to safety. Thereafter, the new experience is integrated to the symbolic universe achieved through previous social interactions. At this level of interpretation, there is an added meaning to the incident, namely, that of the structure of relationships between groups of people on an aggregated level within the parameters of a social hierarchy. This part of the meaning making stems from associations and connections made between perceived group identities and their markers, social hierarchies, prejudices, and practices of violence. At this stage, the new experience may also recursively influence interpretations of previous experiences.

\section{Figure 1. Constitution}

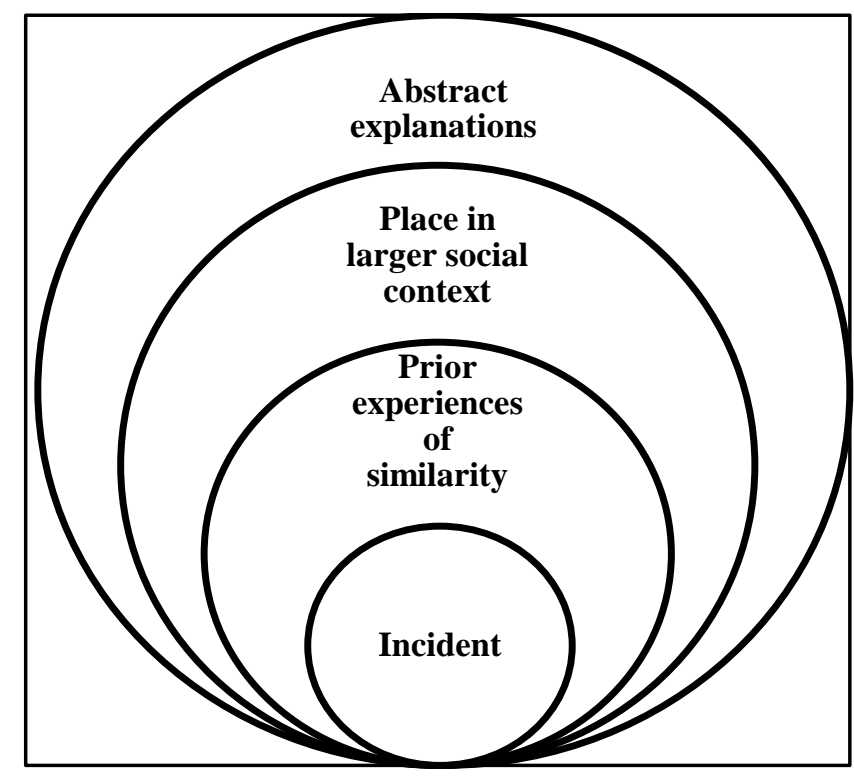

At the final stage of interpretation, the participants use abstract and theoretical explanations to draw meaning from their experiences. These encompass the concepts of various forms of structural oppression, such as racism or misogyny, and occasionally the perceived 
HOW VICTIMS CONCEPTUALIZE THEIR EXPERIENCES OF HATE CRIME

mechanisms or causes of these. The abstract explanation is reductionist in the sense that it is comprised of models that do not take the totality of the experiences of the participants into account.

As such, it is a good tool for communicating experiences, but it also implies that there are no fixed sets of abstract meaning making ascribed to hate crime incidents. Rather, any abstract definition that captures certain clusters of lived experience can be applied. For example, some participants who had experienced racist and/or homophobic slurs were, on one hand, able to navigate those experiences in terms of structural racism, homophobia, and misogyny, and on the other hand, think of them as incidents where drunk teenagers were merely showing off in front of their friends. Consequently, assigning the term 'hate crime' to an experience does not exclude other parallel frameworks of abstract explanations.

\section{Discussion}

The present study has explored how victims define and create meaning of their experiences of hate crime, which is an understudied aspect of hate crime victimization. In summary, victims present prejudice as the primary cause of hate crime, and hate crime is perceived to be structural in origin. The structure is described as a social hierarchy with an idealized norm at the top and a stigmatized 'Other' at the bottom. The presence of this structure is confirmed by experiences of repeat victimization by various offenders. Offenders are held to have been socialized into value systems that proclaim the superiority of certain groups. The prejudice expressed by hate crime incidents is understood as dehumanizing, as it causes offenders to disregard the plurality of identities among their victims and denies victims the possibility to attach content to their own identity markers.

The study has limitations that need to be lifted. Firstly, the meaning making of the participants were occasionally influenced by their academic studies. This implies that the congruency in labels and interpretational models between scientific theories and victims of hate crime is likely to be overstated in the present study. Secondly, the young ages of those in the sample means that it is not representative of the experiences and narratives of victims in other stages of life. The participants shared the meaning making that they had once attached to their experiences during childhood and adolescence in retrospect, but the study lack stories from victims above the age of 36 . Thirdly, only two of the participants had children of their own, meaning that the sample is not a good representation of victims with these kinds of responsibilities. Instead, most participants live by themselves and have a typical student lifestyle which includes many parties and hanging out with friends rather than forming daily habits that revolve around the needs of children or working fixed hours.

With these limitations stated, a few strengths must also be lifted. Firstly, the participants had experiences of hate crime which targeted a variety of group identities. The study included participants from various racial and cultural backgrounds, sexual and gender identities and expression, and confessions of faith. Secondly, it included participants with a wide set of victimization experiences. The incidents span from harassment and threats to physical violence and rape. The relationship to the offenders varied too - a few had been targeted by 


\section{HOW VICTIMS CONCEPTUALIZE THEIR EXPERIENCES OF HATE CRIME}

family and partners, but all had been targeted by strangers. Lastly, the identity markers of the victims varied in their visibility, meaning that the participants represent victims with both high and low visibility.

The results show that there is little consistency between the conceptualization made by the participants in the present study and those of legal frameworks. Although the some labels are used both in legal frameworks and by victims, such as violation, they are loaded with different content by these actors. While the present legislation in Sweden strictly limits hate crime to acts defined in the penal code, victims tend to have difficulties distinguishing criminalized acts from other forms of prejudice, as the master signifiers used by victims refer to the system of oppression expressed in the act rather than its legal status. The victims also tended to assign less value to specific group belongings, holding that it is selection on the basis of prejudice that gives hate crime its specific dynamic rather than fixed categories and specific acts as in legislation. The victims further concur with Lawrence's (1994) assertion that the animus model is the one by which hate crime is most easily identified, but they also include incidents that evidently belong to the discriminatory selection model as hate crime despite their ambiguity.

The victims formed an understanding of hate crime as part of larger hierarchical structures and thereby concur with the narratives lifted among special interest organizations and with Perry's (2001) definition of hate crime. This process ought to be understood in terms of retention, the process by which incidents in the present are given meaning and content in the light of previous experiences, as well as protention, which refers to expectations in the future. From a larger perspective, this also mirrors the victims' notion of their own positions in society. The victims also integrated parts of Chakraborti and Garland's (2012) theoretical development when assigning higher risk to certain places and contexts. The common features of these places and contexts were that certain forms of prejudice are common among a large percentage of the individuals who reside there. In contrast to Chakraborti and Garland (2012), it is the concentration of prejudice that is perceived to be the risk rather than individual vulnerability.

Lastly, the victims partly concurred with Iganski's (2001) assertion that hate crime is a perceived attack on the self of the victim. The victims in the present study perceive hate crime to be a form of attack on their selves, but held that this attack is performed through the denial of self-representation. In line with previous research, the participants expressed a wide range of emotions attached to the denial of self-representation, including anger, grief, and futility. At the same time, victims tended to hold a more detached attitude regarding their experiences in cases where the offender wrongly interpreted their identity markers. It is further likely that aggregated experiences of micro-aggression, discrimination, and repeat hate crime victimization influence the psychological resilience of victims, as hate crime is perceived to be but one expression of a larger social hierarchy and stigmatization.

In light of these results, the authors want to lift policy implications for key actors within the justice system. There is an evident need for mutual knowledge exchanges between the justice system and special interest organizations working with minority rights. Actors within the justice system, such as the police and prosecutor authorities, can improve upon their 


\section{HOW VICTIMS CONCEPTUALIZE THEIR EXPERIENCES OF HATE CRIME}

knowledge regarding the labels and interpretational models that victims of hate crime apply to their experiences as well as information of the derogatory labels used by offenders in these incidents. Such knowledge will extend the capacities of these authorities to identify and prosecute hate crime. Further, special interest organizations can distribute information to members and communities regarding the legal status of various acts and thereby hold the potential to counteract the widespread normalization of threats and harassment that representatives of various minority groups in Sweden attest to (SOU, 2000:88; Mångkulturellt centrum, 2014:1; RFSL, 2017).

\section{References}

Al-Hakim, M. (2014) Making a home for the homeless in hate crime legislation. Journal of Interpersonal Violence, 30(10): 1755-1781. doi: 10.1177/0886260514549197

Andersson, M (2018) Hate crime victimization: consequences and interpretations. Malmö University, Faculty of Health and Society, 2018:5.

Arendt, H. (1973) The origins of totalitarianism. London: Hartcourt.

Boeckmann, R., Turpin-Petrosino, C. (2002) Understanding the harm of hate. Journal of Social Issues, 58(2): 207:225. doi: 10.1111/1540-4560.00257

Bjurwill, C. (1995) Fenomenologi. Lund: Studentlitteratur.

Campbell, R. (2014) Not getting away with it: linking sex work and hate crime in Merseyside. In: Chakraborti, N., Garland, J. (Eds) Responding to hate crime: the case for connecting policy and research. Bristol: Policy Press.

Chahal, K. (2017) Supporting victims of hate crime: a practitioners guide. Bristol: Policy Press.

Chakraborti, N., Garland, J. (2012) Reconceptualizing hate crime victimization through the lens of vulnerability and 'difference'. Theoretical Criminology, 16(4): 499-514. doi: $10.1177 / 1362480612439432$

Christie, N. (1986) The ideal victim. In: Fattah, E A. (Ed) From crime policy to victim policy. London: Palgrave Macmillan.

Ds 2014:8 Den mörka och okända historien vitbok om övergrepp och kränkningar av romer under 1900-talet. Regeringskansliet: Arbetsmarknadsdepartementet.

Garland, J., Hodkinson, P. (2015) Alternative subcultures and hate crime. In: Hall, N. Corb, A. Giannasi, P. Grieve, G. (Eds) The Routledge International Handbook on Hate Crime. New York: Routledge.

Green, D., McFalls, L., Smith, J. (2001) Hate crime: an emergent research agenda. Annual Review of Sociology, 27: 479-504. doi: 10.1146/annurev.soc.27.1.479

Herman, J L. (2015) Trauma and recovery. London: Pandora. 


\section{HOW VICTIMS CONCEPTUALIZE THEIR EXPERIENCES OF HATE CRIME}

Husserl, E. (1913:2004) Ideér till en ren fenomenologi och fenomenologisk filosofi. Stockholm: Max Niemeyer Verlag and Thales.

Husserl, E. (1936:1970) The crises of the European sciences and transcendental phenomenology. Evanston: Northwestern University Press.

Iganski, P. (2001) Hate crime hurt more. American Behavioral Scientist, 45(5): 626-638. doi: $10.1177 / 0002764201045004006$

Iganski, P., Lagou, S. (2015) Hate crimes hurt some more than others: implications for the just sentencing of offenders. Journal of Interpersonal Violence, 30(10): 1696-1718. doi: $10.1177 / 0886260514548584$

Iganski, P., Levin, J. (2015) Hate crime a global perspective. London: Routledge. Jenness, V., Grattet, R. (2001) Making a hate crime: from social movement to law enforcement. New York: Russell Sage Foundation.

Karmen, A. (2010) Crime victims an introduction to victimology. Wadsworth: Belmont.

Lawrence, F M. (1994) The punishment of hate: toward a normative theory of bias-motivated crimes. Michigan Law Review, 93(2): 320-381. doi:

Lindegren, M. (2004) Brottsoffer i rättsprocessen om ideala offer och goda myndigheter. Stockholm: Jure Förlag.

Lyons, CJ., Roberts, A. (2014) The difference "hate" makes in clearing crime: an event history analysis of incident factors. Journal of Contemporary Criminal Justice, 30(3): 268289. doi: $10.1177 / 1043986214536663$

Mason-Bish H (2014) Beyond the Silo: Hate Crime and Intersectionality. In: Hall, N et al. (eds) (2014) International Handbook of Hate Crime. London: Routledge.

McDewitt, J., Balboni, J., Garcia, L., Gu, J. (2001) Consequences for victims, a comparison of bias- and non-bias-motivated assaults. The American Behavioural Scientist, 45(5): $697-$ 713. doi: $10.1177 / 0002764201045004010$

Mångkulturellt centrum 2014:1 Afrofobi. En kunskapsöversikt över afrosvenskars situation i dagens Sverige.

Noelle, M. (2002) The ripple effect of the Mathew Shepard murder. American Behavioral Scientist, 46(1):27-50. doi: 10.1177/0002764202046001004

Pezzelia, F., Fetzer, M. (2017) The likelihood of injury among bias crimes: an analysis of general and specific bias types. Journal of Interpersonal Violence, 32(5): 703-729. doi: $10.1177 / 0886260515586374$

Perry, B. (2001) In the name of hate understanding hate crimes. London: Routledge.

Perry, B. (2015) Exploring the community impacts of hate crime. In: Hall, N., Corb, A., Giannasi, P., Grieve, G. (Eds) The Routledge International Handbook on Hate Crime. New York: Routledge. 


\section{HOW VICTIMS CONCEPTUALIZE THEIR EXPERIENCES OF HATE CRIME}

RFSL (2017) Förtroende att stärka om hbtq-personers förtroende för olika samhällsinsatser och vad som behöver förbättras. Riksförbundet för homosexuellas, bisexuellas, transpersoners och queeras rättigheter.

Salter, M., McGuire, K. (2014) Issues and challenges in the application of Husserlian phenomenology to the lived experience of hate crime and its legal aftermath. Journal of Interpersonal Violence, 30(10): 1782-1802. doi: 10.1177/0886260514548582

SOU 2000:88 Organiserad brottslighet, hets mot folkgrupp, hets mot homosexuella, m.m. straffansvarets räckvidd. Justitiedepartementet.

UKÄ (2013) Universitet och högskolor, årsrapport 2014. Universitetskanslerämbetet.

Willis, D. (2009) Meanings in adult mate victims' experiences of hate crime and its aftermath. Issues in Mental Health Nursing: 29(6): 567.584. doi: 10.1080/01612840802048733

Wacholz, S. (2005) Hate crimes against the homeless: warning-out new England style. The Journal of Sociology \& Social Welfare. 32(4): 141-163. Retrieved from $\mathrm{http}$ ://scholarworks.wmich.edu/cgi/viewcontent.cgi?article $=3119 \&$ context $=\mathrm{jssw}$

Williams, M. Tregidga, J. (2013) All Wales hate crime research project: time for justice. Race Equality First and Cardiff University. 